\title{
anatomy
}

Original Article

www.anatomy.org.tr

Received: Fuly 18, 2016; Accepted: December 8, 2016

doi:10.2399/ana.16.050

\section{Age-related morphological changes in the thymus of indigenous Large White pig cross during foetal and postnatal development}

\author{
Casmir Onwuaso Igbokwe, Kelechi Ezenwaka \\ Department of Veterinary Anatomy, Faculty of Veterinary Medicine, University of Nigeria, Nsukka, Nigeria
}

\begin{abstract}
Objectives: The thymus is found in all vertebrates, the structure of the thymus differs markedly among species. This study investigated the gross anatomy, morphometric and histological changes of the thymus in the indigenous Large White pig cross at various ages of foetal and postnatal periods.

Methods: The study used slaughter house specimens obtained after adequate health inspection and slaughter. A total of fifty three samples of thymus collected from foetal, prepubertal and pubertal pigs with varied weights were used for gross and histological study.

Results: The absolute thymus weight showed significant $(p<0.05)$ increase in size with advancing foetal age, but the increment was not significant in the postnatal stage. The capsule was initially thin and indistinct at 30-45 days thymus, but increased in thickness with progression of gestation. A distinct evidence of lobulation was observed in foetuses of 46-58 days of gestation. Interlobular septa matured and increased in vascularization with age, such that they were highly vascularized at 77-90 days thymus. The boundary of cortex-medulla was partially distinguishable at 46-58 days foetuses and distinctively demarcated at 60-75 days of gestation. Various sizes of lymphocytes were apparent in the cortex at 60-75 days impacting a strong basophilic colour to the cortex. Rudiments of epithelial cells were seen as eosinophilic clumps at 30-45 day thymus. Apparently well differentiated epithelial cells with dense consistency were observed at 46-58 days thymus. Macrophages were seen at the 95-113 days and were quite distinct at the prepubertal and pubertal age. Early forms of Hassal's corpuscles were present at 46-58 day thymus and increased in number with age.
\end{abstract}

Conclusion: The present study has demonstrated that the morphology of the thymus changed with age and the cellular components of the thymus attain morphological maturity during the late foetal period and may be involved in moderate prenatal immunological functions.

Keywords: foetal; indigenous pigs; morphology; thymus

Anatomy 2017;11(1):12-20 @2017 Turkish Society of Anatomy and Clinical Anatomy (TSACA)

\section{Introduction}

The thymus is part of the lymphatic system that is found in all vertebrates, with the exception of the jawless fish, such as lampreys. ${ }^{[1]}$ It is considered a primary organ due to its central role as being the centre for development and 'training' of T cells, which then disperse throughout the body to direct and assist with immunity. Thymus together with parathyroids is derived from single primordium in the third pharyngeal pouches of the endodermal foregut of most domestic animals. These two organs eventually migrate to their final location and separate during embry- onic development. ${ }^{[2]}$ For instance, in the mouse, the primordial in the third pharyngeal pouch are completely separated into thymus and parathyroid domains at embryonic day $11.5 .{ }^{[3]}$ By embryonic day 12 , the thymus-parathyroid primordia have completely detached from the pharynx and started their separation into two discrete organs and their migration towards the anterior of the thoracic cavity. The thymus development is a highly dynamic and complex process, involving reciprocal tissue interactions between epithelial cells derived from endoderm of the anterior foregut and neural crest-derived mesenchyme to 
form rudiments of thymus. Thymocyte progenitors are attracted to this rudiment and support their differentiation and functional maturation into self-tolerant diverse groups of $\mathrm{T}$ cells are supported. ${ }^{[1]}$

The structure of the thymus differs markedly among species. The differences include the number per animal, anatomical position, structure of the thymic lobes, developmental origin and developmental processes. ${ }^{[4]}$ The anatomical position of the thymus in the neck (cervical thymus) and or in the thorax (thoracic thymus), differ amongst vertebrates. Most domestic animals have dominant cervical thymus. ${ }^{[5]}$ The mammalian thymus usually undergoes atresia and begins to involute around the period of young and adulthood pubescence). In this period, connective and adipose tissue invade the organ as the thymic parenchyma becomes reduced. There is progressive loss of mostly immature, cortical thymocytes and clear reorganization of the organ architecture, involving the loss of definition of the cortex and medulla. ${ }^{[6]}$ Stressors, such as cold and pregnancy, can cause the thymus to involute more severely. ${ }^{[7]}$ It also varies amongst species, strain and sex.

The local breed of pig (swine) was used for this study because swine is considered one of the major animal species of choice apart from rodents, used in translational research especially in preclinical toxicological testing of drugs. ${ }^{[8]}$ In addition, most of the available literature is on development of the thymus in laboratory animals (rats, mice, rabbits and guinea pigs) and other exotic species and only a few domestic animals of the tropical climate have been investigated. ${ }^{[9,10-13]}$ Even so, there was little emphasis on histological changes during foetal growth. It is expected that there would be variations in structure from exotic species in the time of histological maturation of the thymus in the indigenous cross because of differing feeding, management and climatic factors in the tropical environment.

The main objective of this investigation is to evaluate the gross anatomy, morphometric and histological changes of the thymus in the indigenous Large White pig cross at various ages of foetal and postnatal periods, with emphasis on histological changes during growth. The baseline information obtained useful in prenatal and postnatal clinical and pathological diagnosis of health conditions in the indigenous Large White pig cross.

\section{Materials and Methods}

\section{Animals}

The study samples were obtained from apparently healthy adult indigenous Large White cross slaughtered for meat at the Nsukka slaughter house. They comprised thymus from 36 foetuses (males and females), of pregnant animals slaughtered unknowingly, seven prepubertal and ten pubertal pigs (males and females). Age estimation of the foetuses was done using Crown-Rump-Length (CRL) which was measured with threads and meter rule. The age was estimated with a chart for estimation using CRL in domestic animals by McGeady et al. ${ }^{[14]}$ and the pre-pubertal and pubertal age were estimated by dentition ${ }^{[15]}$ and farm record information from pig sellers. The weights of all animal were obtained with mobile scale for postnatal period (Tefal Electronic kitchen scale, Rumilly, HauteSavoie, France) and top loader Mettler weighing balance (Mettler Toledo Inc., Greifensee, Switzerland) for foetuses. The sex of the animal was not considered in this present study. The Research and Ethics committee of the University of Nigeria, Nsukka, Nigeria approved this work.

Gross dissection by parasternal incision was carried out on the foetuses, while the postnatal samples (prepubertal and pubertal) were obtained after slaughter and before singeing. The thymus in all cases was removed after thorough trimming off the adjacent fat and connective tissue. The thymic weights were measured prior to fixation and following removal of adjacent fat and connective tissue. In the older pubertal pigs, adipose and connective tissues from cranial mediastinum containing thymic tissues were collected and fixed without weighing following methods of other investigators. ${ }^{[16]}$

Fixed tissue sections were processed for study following routine histological procedure. ${ }^{[17]}$ Sections were cut at 6 $\mu \mathrm{m}$, stained with haematoxylin and eosin $(\mathrm{H} \& \mathrm{E})$, and were examined under microscope. Selected tissue sections were captured into a computer with Moticam 2005 camera attachment (Moticam, Xiamen, China). For histometry, the diameters of the Hassal's corpuscles were measured with ocular micrometer calibrated with stage micrometer gauge. The average of transverse and longitudinal diameters was obtained in the spherical and round corpuscles. Several corpuscles per section were randomly measured. Polymorphic corpuscles were ignored. Using IBM SPSS (Statistical Package for the Social Sciences, version 16.0; IBM, Chicago, IL, USA) software, the means and standard error of mean (SEM) of diameter of Hassal's corpuscles were computed for each development age of thymus. Data were analyzed statistically using analysis of variance. Duncan's multiple range test was used to separate variant means, and significance was accepted at $\mathrm{p}<0.05$.

\section{Results}

\section{Gross anatomical observations}

The thymus of the prenatal (foetal) pig in all stages of development was grayish-red in color, soft in consisten- 
cy and consisted of cervical and thoracic parts which were superficially divided into lobules. The cervical part was on the ventro-lateral surface of the neck and was from the origin the digastricus muscle close to the carotid arteries on either side of the neck to the thoracic inlet, where the left and right thymus fused indistinctly. It was related superficially to the cranial portion of the omohyoideus muscle, while the thoracic part was in the precardial aspect of the thoracic cavity and related to the base of the heart (Figures 1a and $\mathbf{b}$ ). In the pubertal pigs, a slight decrease in the size of the thymus was observed. The cervical thymus and remnants of thoracic the thymus was therefore located in the cranial mediasternal space related to the base of the heart amongst copious adipose and connective tissue. It was not clearly identifiable from these surrounding structures.

The gross morphometry and histometry of the thymus during development is shown in Table 1. The thymic absolute weights increased with advance of gestation and the maximum weight was obtained in the prepubertal stage, and followed by a slight decrease in weight in the old adult stage (It was not significant at $\mathrm{p}<$ 0.05). The diameter of the Hassal's corpuscles measured microscopically increased with gestational age and this was significant at foetal ages of development $(\mathrm{p}<0.05)$.

\section{Histological observations}

In the pig fetuses of 30-45 days of gestation, the thymus showed very thin, indistinct capsule covering of the organ and there was no evidence of lobulation. Simple squamous and low cuboidal epithelial cells were seen enveloping the capsule of the organ. Primitive lymphoid cells (lymphoblast) with intermingled mesenchymal connective tissue were present in the parenchyma. The nuclei of these cells varied considerably in size but
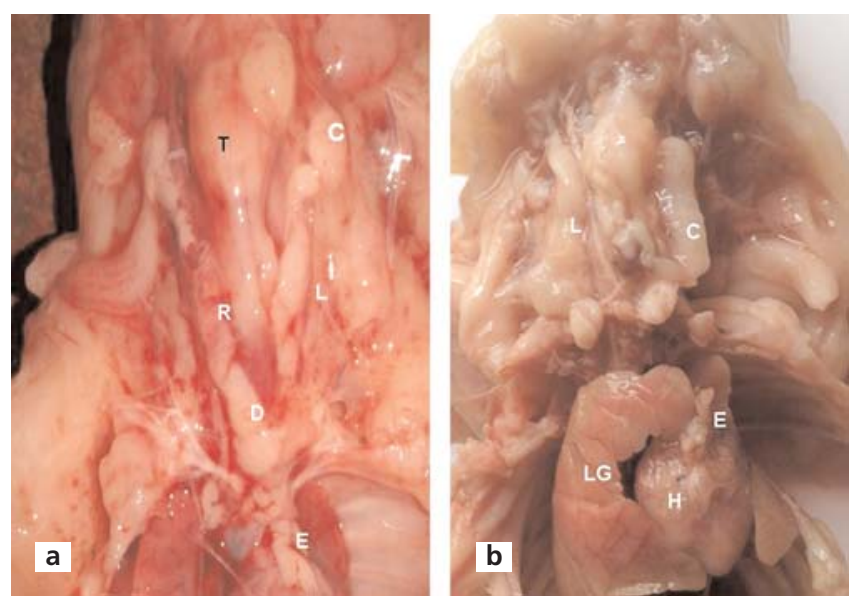

Figure 1. (a) Gross photograph of foetal thymus (77-79 daysl) showing left (L) and right (R) thymus with cervical part (C), thoracic part (E), caudal cervical (D). The heart (H) and trachea (T) are indicated. (b) Relationship of the thymus with other visceral structures are shown, lungs $(\mathrm{LG})$, heart $(\mathrm{H})$, cervical thymus $(C)$ and thoracic thymus (E). Scale bar $=15 \mathrm{~mm}$. [Color figure can be viewed in the online issue, which is available at www.anatomy. org.tr]

showed similar basophilic staining characteristics. The thymus was devoid of blood vessels. There was no demarcation into cortex and medulla, and the inner part of the organ which would later differentiate into the medulla contained large eosinophilic cells that resembled epithelio-reticular cells, few lymphoblast and primordial of Hassal's corpuscles (Figures 2a and b).

In 46-58 days of gestation, there was a very thin capsule covering the organ with evidence of lobulation and a very thin interlobular septae with poor vascularisation. Cells present were lymphoblast, large lymphocytes, small lymphocytes, epithelio-reticular cells and developing macrophages. The thymus partially differentiated

Table 1

Morphometry of the thymus of the Indigenous local cross pig at different ages of development.

\begin{tabular}{|c|c|c|c|c|}
\hline $\begin{array}{l}\text { Estimated age days }(d) / \\
\text { months }(m)\end{array}$ & $\begin{array}{c}\text { Animal } \\
\text { weight (g) }\end{array}$ & $\begin{array}{l}\text { Thymus weight } \\
\text { absolute (g) }\end{array}$ & $\begin{array}{c}\text { Relative thymus } \\
\text { weight }\end{array}$ & $\begin{array}{c}\text { Diameter of Hassal's } \\
\text { corpuscles }(\mu \mathrm{m})\end{array}$ \\
\hline $30-45 \S$ & $13.7 \pm 1.4(8.3-14.1)$ & $0.07 a \pm .01(0.06-0.08)$ & .0054 & $4.4 \mathrm{a} \pm 0.1(3.5-4.3)$ \\
\hline $46-58 \S$ & $77.4 \pm 3.4(66.4-78.3)$ & $0.23^{b} \pm .03(0.21-0.27)$ & .0029 & $3.2^{b} \pm 0.9(7.2-9.1)$ \\
\hline $60-75 \S$ & $170.3 \pm 1.8(142.4-187.6)$ & $0.38 \subset \pm .12(0.32-0.39)$ & .0022 & $10.9^{b} \pm 0.3(8.3-10.8)$ \\
\hline $77-90 \S$ & $238.1 \pm 6.4(232.6-318.4)$ & $0.46 \mathrm{~d} \pm .04(0.41-0.48)$ & .0019 & $16.5{ }^{c} \pm 0.3(14.2-16.7)$ \\
\hline $95-113 \$$ & $1096.5 \pm 5.1(1023.4-10170.9)$ & $1.72 \mathrm{e}_{ \pm .14}(1.65-1.74)$ & .0016 & $19.6 \mathrm{~d} \pm 0.7(18.5-19.8)$ \\
\hline Prepubertal (3-6 m) & $4003.5 \pm 16.3$ & $1.94 f_{ \pm .06}(1.79-1.98)$ & - & $21.6 \mathrm{~d} \pm 0.6(20.4-22.8)$ \\
\hline Pubertal (10-18 m) & $28500.6 \pm 11.3$ & $1.90^{f} \pm .03(1.98-2.01)$ & - & $26.2^{\mathrm{e}} \pm 0.8(25.6-30.1)$ \\
\hline
\end{tabular}

Means in the same column with different superscripts $(a, b, c, d, e, f)$ differ significantly $(p<0.05)$. 

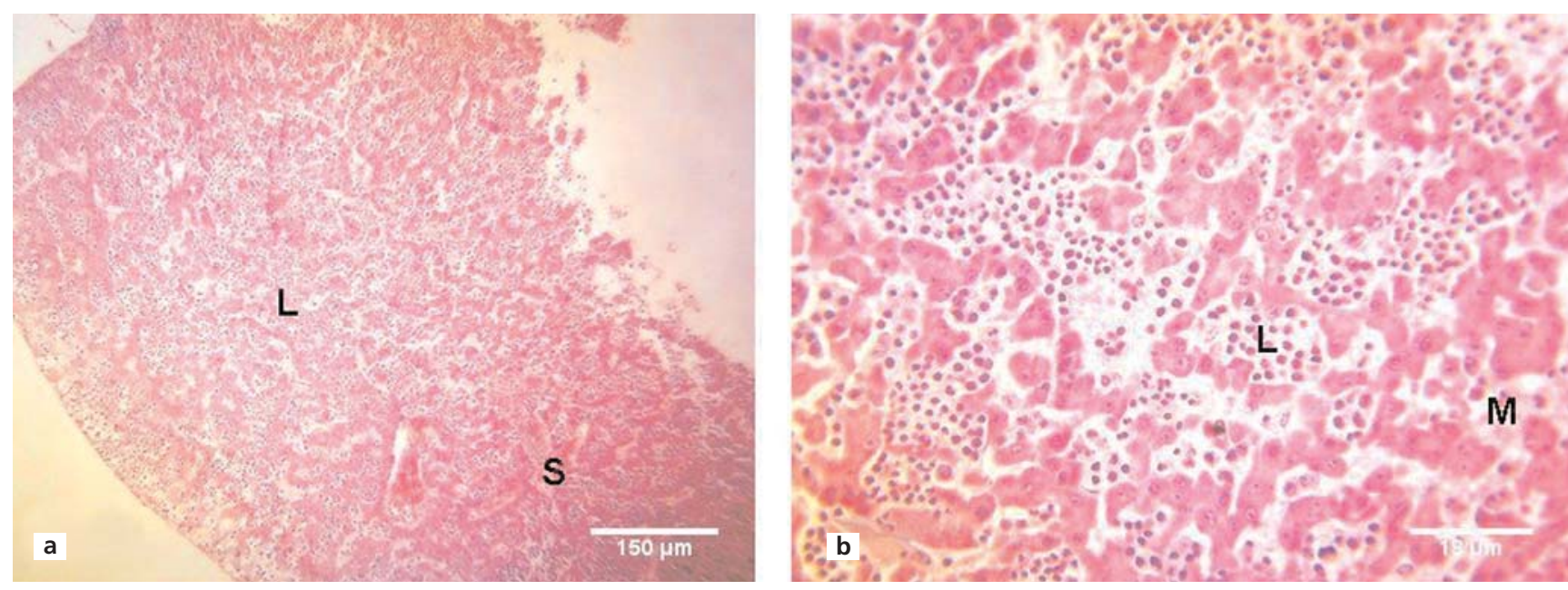

Figure 2. (a) Photomicrograph of thymus at 30-45 days showing rudimentary parenchyma (L) and septa (S). (b) Primitive lymphoid cells with mesenchymal connective tissue (L) and medulla (M). H\&E stain. [Color figure can be viewed in the online issue, which is available at www.anatomy.org.tr]

into cortex and medulla with the medulla containing large cells with slightly eosinophilic cytoplasm that resembled the earlier epithelial cells and a few primitive Hassal's corpuscles (Figures 3a and $\mathbf{b}$ ).

In thymus at gestation days 60-75, the parenchyma cellular components increased in size and differentiation compared to the previous age, and was completely divided by connective tissue septae (interlobular septa). There was an obvious demarcation into cortex and medulla; the medulla cells were less basophilic and less closely packed than the surrounding cortex. Lymphocytes and lym- phoblast were much denser in the cortex. Hassal's corpuscles matured further at this age and were however few in number. Few amorphous Hassal's corpuscles were also seen. The vascularization increased (Figures $4 \mathbf{a}$ and $\mathbf{b}$ ).

The thymus at 77-90 days of gestation was much larger compared to previous ages and completely lobulated with obvious demarcation into cortex and medulla. The medulla cells were less basophilic and less closely packed than the surrounding cortex. Lymphocytes were now much denser in the cortex. Well differentiated and Hassal's corpuscles were seen (Figures $\mathbf{5} \mathbf{a}$ and $\mathbf{b}$ ) and
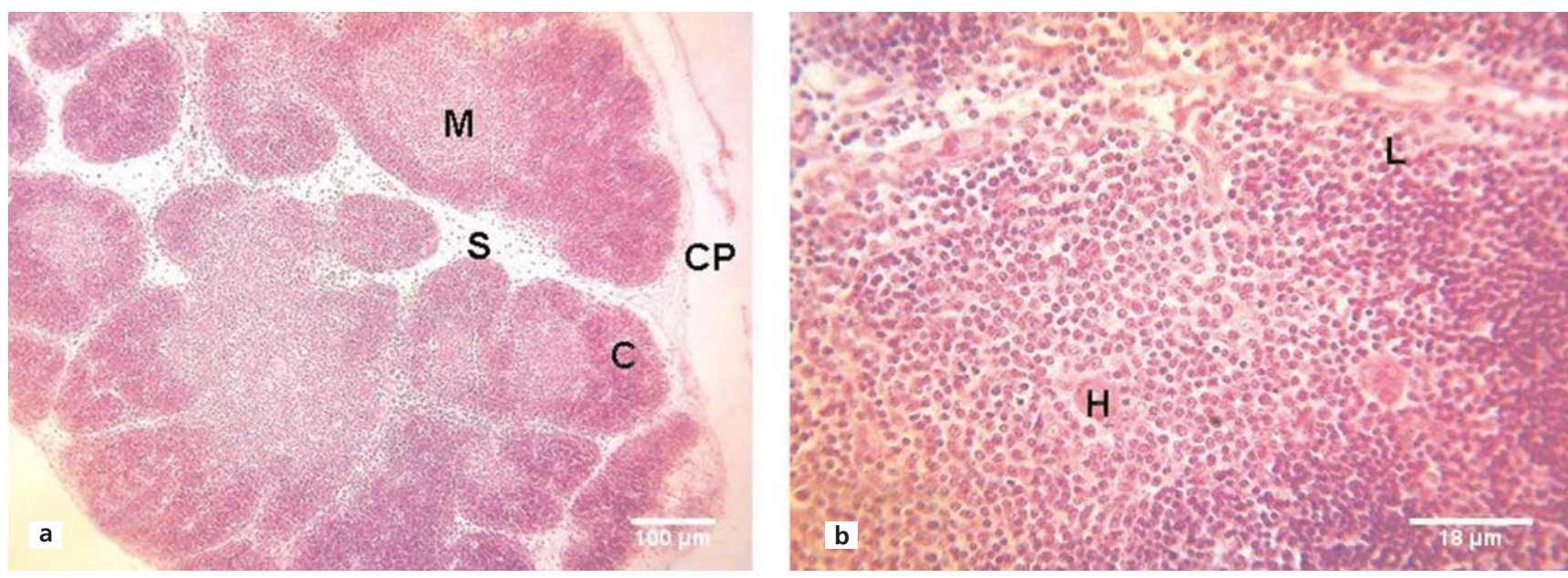

Figure 3. (a) Photomicrograph of thymus at 46-58 days showing lobulated organ with early divisions into cortex (C), medulla (M), interlobular tissue (S) and capsule (CP). (b) Early lymphocytes (L) and primitive Hassal's corpuscles (H). H\&E stain. [Color figure can be viewed in the online issue, which is available at www.anatomy.org.tr] 

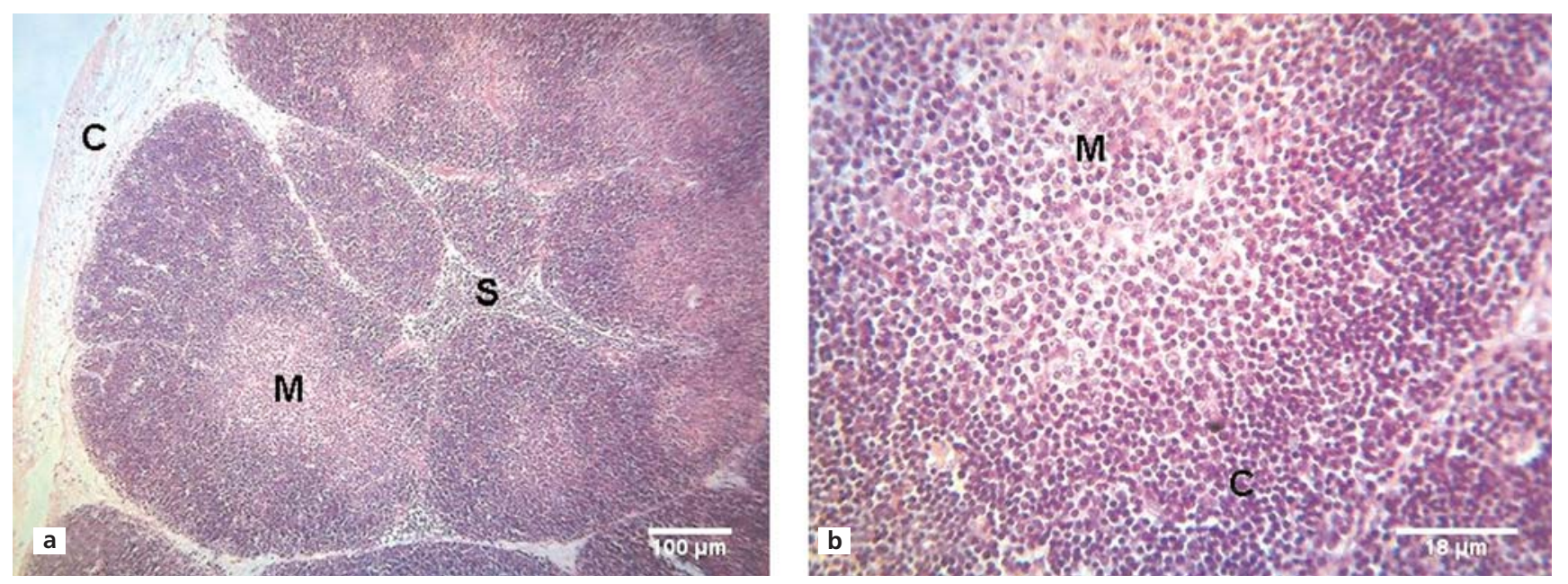

Figure 4. (a) Photomicrograph of thymus at 60 days showing cortex (C), well differentiated parenchyma with medulla (M) and and interlobular septa (S). (b) Medulla (M) with lymphocytes, cortex (C) and Hassal's corpuscles (arrow). H\&E stain. [Color figure can be viewed in the online issue, which is available at www.anatomy.org.tr]

were more in number. The interlobular septae was highly vascularized.

The thymus at $95-113$ gestational days showed a completely lobulated organ with fully differentiated cellular components and with a clear demarcation into cortex and medulla. The medullary cells were less basophilic and less closely packed than the surrounding cortex. Lymphocytes were packed in the cortex making the cortex deeper staining than the medulla. Mature Hassal's corpuscles were seen in the medulla and increased in number from previous age (Figures 6a and $\mathbf{b}$ ).

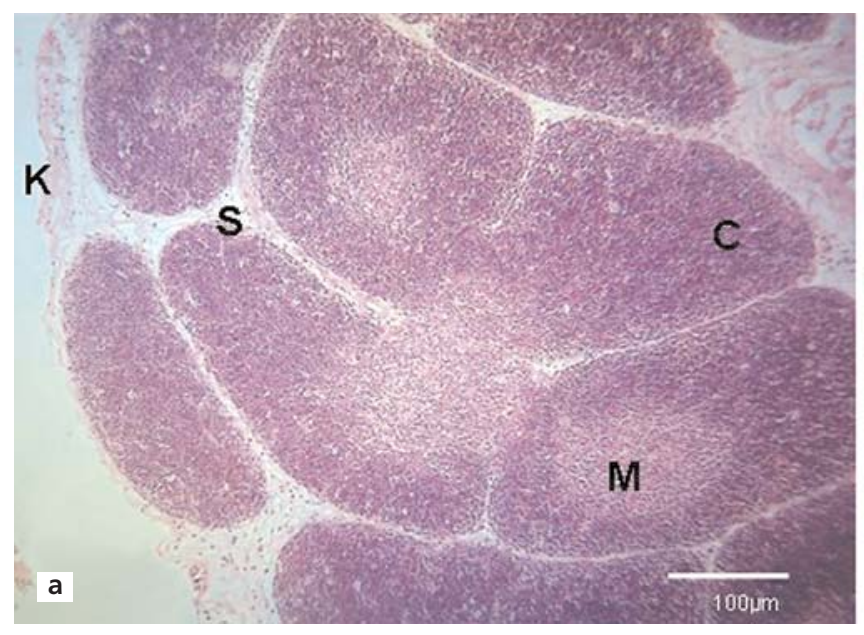

In this study, there were no clear-cut histological differences between the previous late foetal thymus and the prepubertal thymus. However, in the prepubertal thymus (Figures $7 \mathbf{a}$ and $\mathbf{b}$ ), most cellular components including the lymphocytes epithelio-reticular cells, trabeculae and Hassal's corpuscles increased in size and number from what was observed in the previous age. In the pubertal pig thymus of up to one year, Hassal's corpuscles displayed different sizes and shapes, being round or oval and even amorphous ones were present.

The pubertal thymus of up to 18 months (Figures 8a and $\mathbf{b}$ ), showed evidence of morphological thymic invo-

Figure 5. (a) Photomicrograph showing further maturation at 77-90 days with denser cortex of lymphocytes (C) and medulla (M), capsule (K), septa (S). (b) Hassal's corpuscles (H) and lymphocytes (L). H\&E stain. [Color figure can be viewed in the online issue, which is available at www.anatomy. org.tr] 

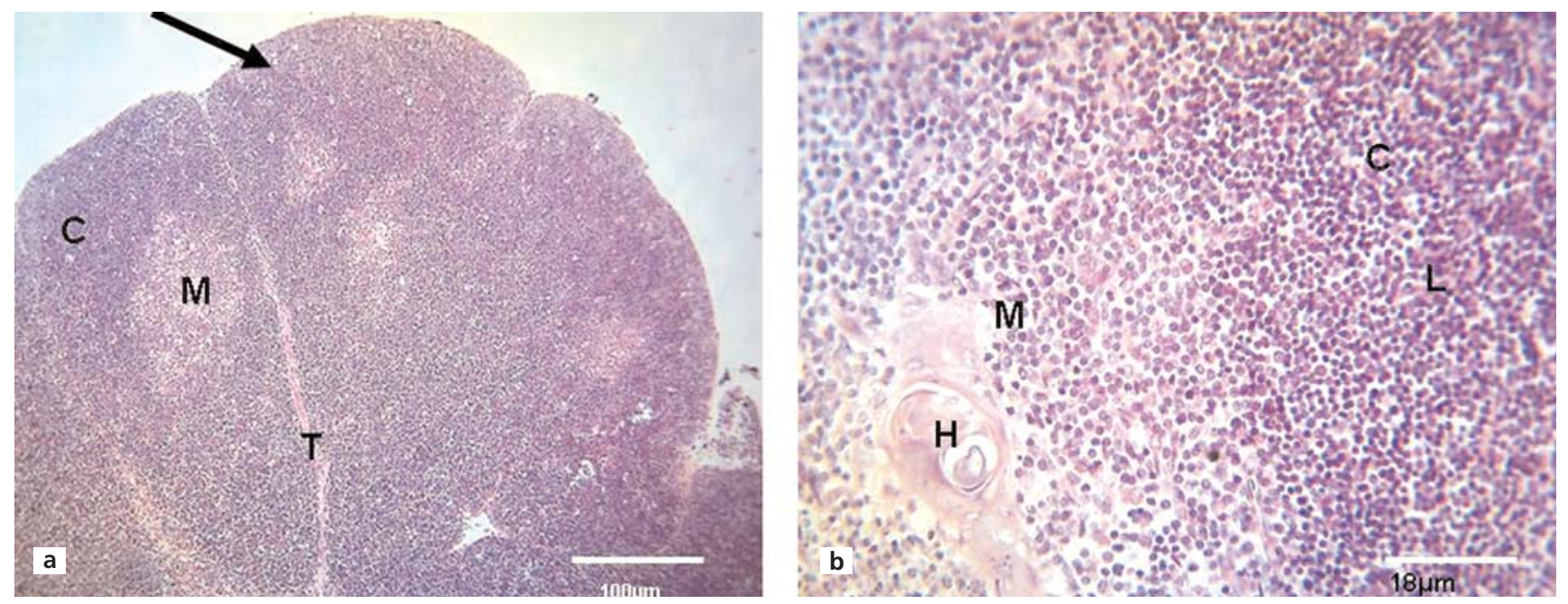

Figure 6. (a) Photomicrograph of thymus at 95-113 days showing copiously lobulated organ with cortex (C), medulla and well formed interlobular septa (T). (b) Cortex (C) with lymphocytes (L) and medulla (M) containing Hassal's corpuscle (H) with varying shape and size. H\&E stain. [Color figure can be viewed in the online issue, which is available at www.anatomy.org.tr]

lution and this was reflected by fewer lymphocytes and epithelial-reticular cells in cortex and medulla. Hassal's corpuscles increased in number with several amorphous ones. Some of these corpuscles and epithelio-reticular cells indicated signs of keratinization and degeneration. There was slight loss in the loss of definition between the cortex and the medulla and increase in the perivascular spaces and the epithelial cells of the medulla became progressively more prominent. Adipose tissue occupied portions of the capsule and interlobular connective tissue.

Generally in development, the capsule was initially indistinct at 30-45 days thymus, but increased in thick- ness with progression of gestation, such that it was surrounded by fat tissue in the pubertal age. A distinct evidence of lobulation was observed in foetuses of 46-58 days of gestation. Interlobular septa matured and increased in vascularisation with age of development, such that they were highly vascularized at 77-90 days thymus. The boundary of cortex-medulla was partially visible at 46-58 days foetuses and was highly demarcated at 60-75 days of gestation. Various sizes of lymphocytes were apparent in the cortex at 60-75 days impacting a strong basophilic colour to the cortex. The compactness of these cells increased with age in the cortex and medul-
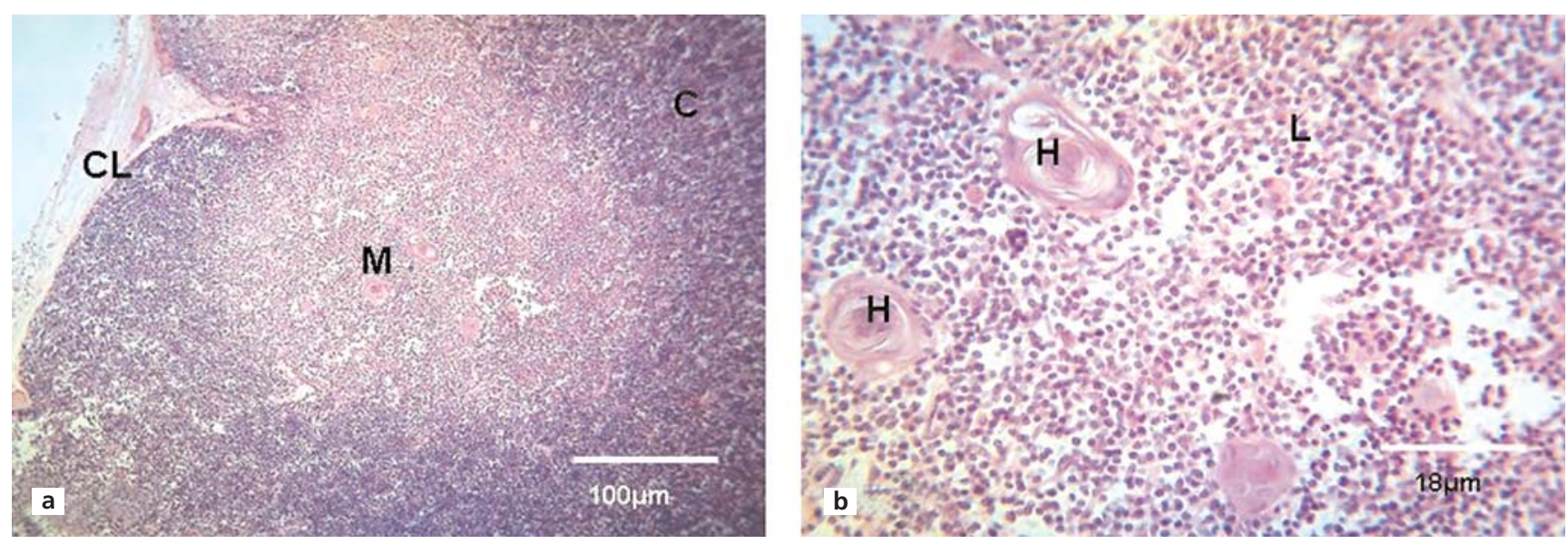

Figure 7. (a) Photomicrograph of prepubertal thymus showing capsule (CL), medulla (M) and cortex (C). (b) showing that medulla (M) contained several whorled pleomorphic corpuscles $(\mathrm{H})$ and lymphocytes $(\mathrm{L})$ in the cortex. H\&E stain. [Color figure can be viewed in the online issue, which is available at www.anatomy.org.tr] 

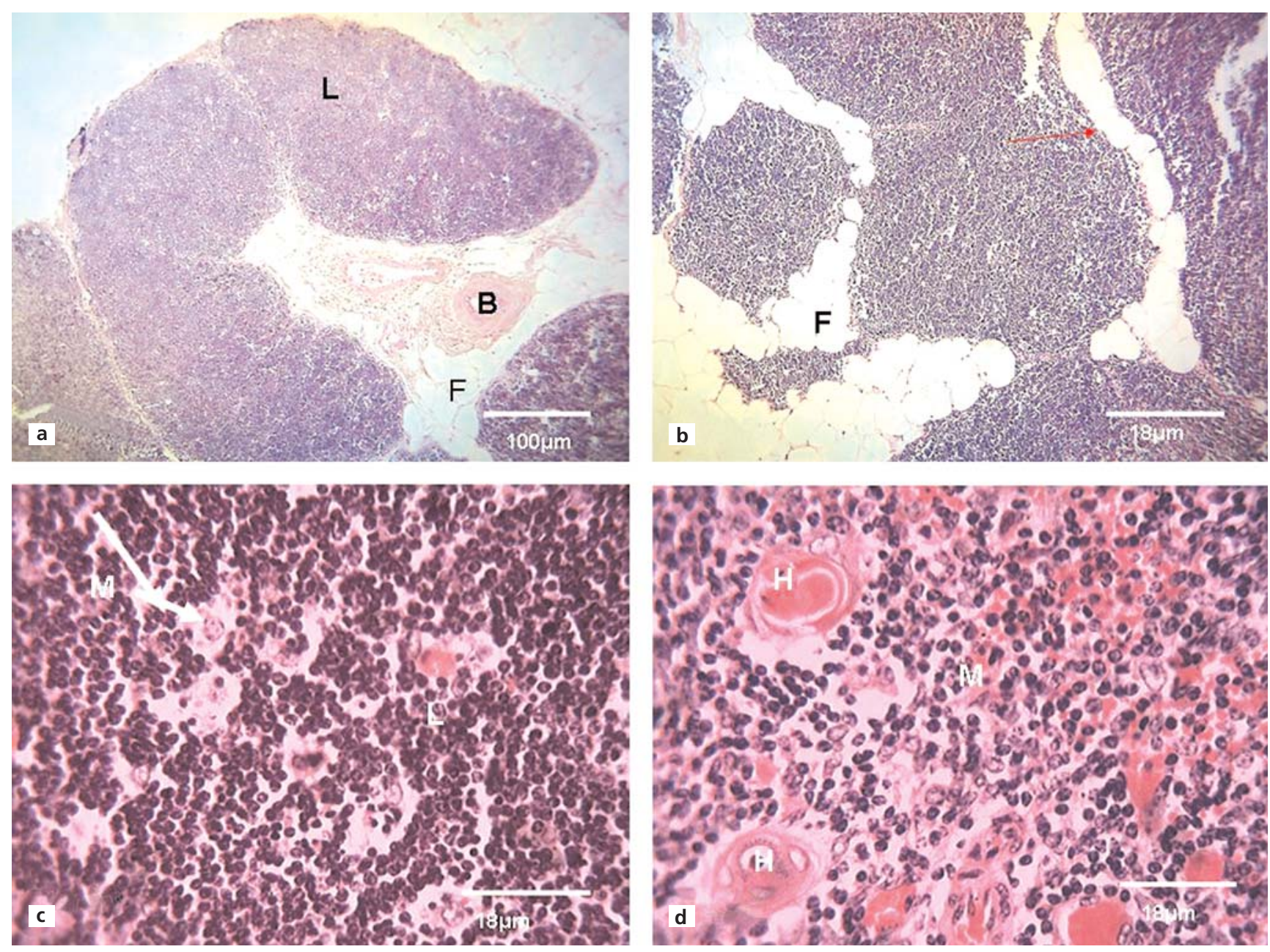

Figure 8. (a) Photomicrograph showing evidence of decrease in size of parenchyma; thymic lobes (L), septa (T) and fatty tissue (F). (b) Evidence of onset of involution by fatty tissue infiltration (F); (c) micrographs of older pubertal thymus showing several macrophages (M) and lymphocytes (L), and in other sections of pubertal thymus (d) Hassal's corpuscles $(\mathrm{H})$ were keratinized, macrophages $(\mathrm{M})$ were also apparent. H\&E stain. [Color figure can be viewed in the online issue, which is available at www.anatomy.org.tr]

la. Rudiments of epithelial cells were seen as eosinophilic clumps at 30-45 day thymus and they increased in number with age of development. Apparently differentiated epithelial cells with dense consistency were observed at 46-58 days thymus. Macrophages were seen at the 95-113 days thymus and were quite distinct at the prepubertal and pubertal age. Early forms of Hassal's corpuscles were seen at 46-58 day thymus and they increased in content and shape with age of development. In the pubertal thymus, varied sizes and shape of Hassal's corpuscles were observed with large whorled eosinophilic appearance.

\section{Discussion}

In the present investigation, the thymus of prenatal pig consisted of cervical and thoracic parts located in located in the cervical region and cranial pericardial mediastinum. They were initially unlobulated in early fetuses of 30-45 days and gradually increased in size and lobulation with age. This observations has been reported in the ox ${ }^{[14,18]}$ goat ${ }^{[11]}$ buffalo ${ }^{[10]}$ and pig. ${ }^{[18]}$ Generally mammals such as sheep, cattle, goat, pigs and horse possess distinct cervical thymuses in addition to the thoracic thymus. In this present report, lobulation was noticed at 46-58 days foetal thymus, while Prasad et al. ${ }^{[11]}$ reported the occurrence of lobulation in goat foetuses of 49-73 days of gestation. This shows the variability of formation of lobules of thymus in animal species. In addition the location of the thymus was more consistent in the cranial pericardial mediastinum of the thoracic cavity in the older pubertal pigs. However, in the guinea pig thymus, unlike other mammals, remains a purely cervical organ. This is due to the greater reduction 
of size of thymus due to age-related physiological involution as reported in hybrid pigs by some investigators. ${ }^{[12]}$ Physiological involution is associated with decrease in the cellular components of thymus including lymphocytes and epithelio-reticular cells of the organ. ${ }^{[19]}$

In this study, there was adherence of the left and right portions of the cervical thymus to form a mass and its connection beyond by a cervico-thoracic isthmus to the thoracic part of the thymus. This finding is similar to findings of in sheep foetus ${ }^{[0]}$ and in buffalo foetus. ${ }^{[10]}$ In addition, the left and right portions of the thymus terminated as a dense lobulated mass on either side of the lar$y n x$ as also observed in the sheep foetus ${ }^{[0]}$ and in some other domestic animals. ${ }^{[18]}$ The relationship of the thymus to other structures and organs in the neck and thoracic cavity seen in pig foetuses in this study is similar to findings also reported by other authors. ${ }^{[18]}$

The absolute mean weights of the thymus were significantly higher in the late prenatal stages as compared to the mid prenatal and early prenatal stages in the present study. It is similar to the findings in developing pigs ${ }^{[19]}$ In addition an overall mean size and weight of thymus showed an increase with advancing of gestation was also reported by some researchers. ${ }^{[1,20]}$ This may suggest onset of remarkable immunological function during the last term of prenatal foetal life. In the present report, the thymus reached it absolute maximum weight in the prepubertal age. Some investigators reported that the maximum thymic weight is reached in the late foetal period in the sheep and Japanese serows (Capricornis crispus). ${ }^{[21]}$ The variations may be related to species differences and climate.

The general histological structure of thymus during the gestational age showed remarkable immaturity in the early foetal age. Most of the typical structural components including capsule, cortex and medulla with lymphocytes, epithelial reticular cellular cells and Hassal's corpuscles in medulla amongst others were very sparse and may not support optimum function. In addition, blood, lymph vessels and nerves were rarely seen at this early foetal age. In late foetuses these components were fully differentiated to possibly support prenatal thymic function. There were numerous lobules and their differentiation into cortex and medulla. There were also presence of thymic corpuscles in the late foetal stage and it increased with age. Similar observations have been seen earlier in prenatal pigs. ${ }^{[2]}$ Functionally active thymic lobules are characterized by the presence of the cortex, medulla and Hassal's corpuscles. ${ }^{[13]}$ These functional components also increased in the prepubertal and early pubertal thymuses. But in the older pubertal thymuses, evidence of involution was noticed in sections and macrophages increased in number. At the pubertal age of about 18 months, lymphocytes and macrophages in its individual lobules were identified along with the cortex and medulla. Adipose tissues were also present in the interlobular tissue and the interlobular tissue was thickened by these fat cells. It indicated early signs of involution. Hassal's corpuscles changed in form with age. In late foetal thymus, it consisted of central degenerated hyaline mass, surrounded by concentrically arranged reticular cells. In older pubertal thymus, signs of polymorphism, keratinization and merging of corpuscles were evident and represented age-related involution. Hassal's corpuscles may have phagocytic function for those lymphocytes that could not mature while moving from cortex into the medulla and could not cross the blood-thymus barrier. It is known that those lymphocytes which had not acquired the specific markers on their membranes are phagocytosed by Hassal's corpuscles. ${ }^{[2]}$ Hassal's corpuscles have also been used as indicators of the degree of age-related thymus involution in most mammals including humans. ${ }^{[23]}$ These features of involution have been observed in aged cattle of 2-5 years and more ${ }^{[13]}$ Further studies will examine very old pigs of over 3 years to ascertain the progress of involution. It is known that many intrinsic and extrinsic factors may contribute to age-associated thymic involution and not much is known about the mechanisms that lead to thymic involution. ${ }^{[24]}$ There are many unanswered questions as to what initiates this process and when exactly it begins. Some investigators found the involution of the thymus in pigs of about 180 days ${ }^{[2]}$ which is contrary to the present report. At the growing age, it is known that the thymus does not undergo a complete involution; part of the functions are maintained in some secretory and hematopoetical insulary cells. ${ }^{[22]}$ In cattle and sheep, the thymus involutes also with increasing age with complete involution by 6 years of age in cattle and marked involution evident in 2-year-old sheep. ${ }^{[2]}$ Macrophages were encountered in the late foetal and postnatal stages of development in this study. They function in phagocytosis. They characteristically contain nuclear debris in the cytoplasm, presumably coming from lymphocytes after programmed cell death (apoptosis). They increased in number with age of development of the thymus. Macrophages may also contribute to intrathymic precursor T-cell maturation. ${ }^{[26]}$ The present preliminary report will enhance further studies on morphological changes of thymus in younger and older pubertal pigs using more samples and advance anatomical techniques. 


\section{Conclusion}

This study has demonstrated that the gross size of the thymus changes with age of development and that the cellular components of the thymus attains morphological maturity during the late foetal period with evidence of some prenatal immunological functions. Early histological signs of age-related involution were observed in the young pubertal pigs, showing slowing down of immunological response.

\section{References}

1. Boehm T. Thymus development and function. Curr Opin Immunol 2008;20:178-84.

2. Gordon J, Manley NR. Mechanisms of thymus organogenesis and morphogenesis. Development 2011;138:3865-78.

3. Gordon J, Bennet AR, Blackburn CC, Manley NR. Gcm2 and Foxn1 mark early parathyroid- and thymus-specific domains in the developing third pharyngeal pouch. Mech Dev 2001;103:141-3.

4. Ge Q, Zhao Y. Evolution of thymus organogenesis. Dev Comp Immunol 2013;39:85-90.

5. Jordan RK. Development of sheep thymus in relation to in utero thymectomy experiments. Eur J Immunol 1976;6:693-8.

6. Bodey B, Bodey B Jr, Siegel SE, Kaiser HE. Involution of the mammalian thymus, one of the leading regulators of aging. In Vivo 1997; 11:421-40.

7. Goldbach KJ. Histological and morphometric investigation of the thymus of the Florida manatee (Trichechus manatus latirostris). MSc Thesis, University of Florida, FL, USA; 2010.

8. Swindle MM, Makin A, Herron, AJ, Clubb FJ, Frazier KS. Swine as models in biomedical research and toxicology testing. Vet Pathol 2012; 49:344-56.

9. Muthiah K, Jeeferson JJ, Lalitha PS. Morphometry of thymus in sheep foetus. Indian Journal of Veterinary Anatomy 1995;11:35-9.

10. Prakash A, Chandra G. Some gross observations on the prenatal thymus of buffalo (Bubalus bubalus). Indian Journal of Veterinary Anatomy 1999;11:178.

11. Prasad M, Prakash A, Archana M, Farooqui M, Singh, SP. Gross biometrical observations on prenatal thymus of goat (Capra hircus). The Haryana Veterinarian 2011;50: 37-9.
12. Yugesh K, Jothi SS, Ramganathan K, Jayaraman P, Chavalin V, Sujatha N. Microscopic and microscopic study of thymus of pig. IOSR Journal of Dental and Medical Sciences 2014;13:52-5.

13. Gasisova AI, Atkenova AB, Ahmetzhanova NB, Murzabekova LM, Bekenova AC. Morphostructure of immune system organs in cattle of different age. Anat Histol Embryol 2017;46:132-42.

14. McGeady TA, Quinn PJ, Fitzpatrick EA, Ryan MT. Veterinary embryology. Oxford (UK): Blackwell Publishing; 2006. p. 346-8.

15. Dyce KM, Sack, WO, Wensing CJG. Textbook of veterinary anatomy, 3rd ed. London; Saunders; 2002. p. 258.

16. Kuper F, Schuurman, HJ, Vos JG. Pathology in immunology. In: Methods in immunotoxicology. In: Burleson JD, Munson A, editors. New York (NY): Wiley-Liss; 1995. p. 397-436.

17. Bancroft JD, Gamble M. Theory and practice of histological techniques. 5th ed. Churchill Livingstone: Toronto; 2002. p. 34-78.

18. Venzke WG. Thymus. In: Sisson and Grossman's the anatomy of domestic animals. Getty R, editor. Vol. 1. Philadelphia (PA): WB Saunders Company; 1975. pp. 1359.

19. Pearse G. Normal structure, function and histology of the thymus. Toxicol Pathol 2006; 34:504-14.

20. Baishya G, Kalita A, Sarma K, Borthakur M. Ontogeny of thymus in crossbred pig-gross anatomical studies. Indian Journal of Veterinary Anatomy 2000; 12: 210.

21. Sugimura M, Suzuki Y, Atoji Y, Sugano M, Tsuchimoto N. Morphological studies on thymus of Japanese serows (Cappricornis crispus). Research Bulletin of the Faculty of Agriculture, Gifu University 1983;48:113-9.

22. Sincai M, Marcu A. Perculiary aspects about development of thymus in pigs. Ciencia Rural Santa Maria 1994;24:117-9.

23. Yurchinskij VJ. Age-related morphological changes in Hassal's corpuscles of different maturity in vertebrate animals and humans. Advances in Gerontology 2016;6:117-22.

24. Rezzani R, Nardo L, Favero G, Peroni M, Rodella LF. Thymus and aging: morphological, radiological, and functional overview. Age (Dordr) 2014;36:313-51.

25. Reynolds JD, Morris B. The evolution of Peyer's patches in fetal and postnatal sheep. Eur J Immunol 1983;13:627-35.

26. Schuurman HJ, Kuper CF, Kendall MD. Thymic microenvironment at the light microscopic level. Microsc Res Tech 1997;38:216-26.

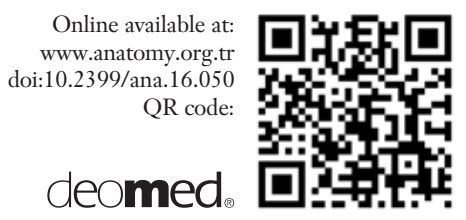

Correspondence to: Casmir O. Igbokwe, PhD

Department of Veterinary Anatomy, Faculty of Veterinary Medicine,

University of Nigeria, Nsukka, Nigeria

Phone: +2348034930393

e-mail: casmir.igbokwe@unn.edu.ng

Conflict of interest statement: No conflicts declared.

This is an open access article distributed under the terms of the Creative Commons Attribution-NonCommercial-NoDerivs 3.0 Unported (CC BY-NCND3.0) Licence (http://creativecommons.org/licenses/by-nc-nd/3.0/) which permits unrestricted noncommercial use, distribution, and reproduction in any medium, provided the original work is properly cited. Please cite this article as: Igbokwe CO, Ezenwaka K. Age-related morphological changes in the thymus of indigenous Large White pig cross during foetal and postnatal development. Anatomy 2017;11(1):12-20. 